\title{
Not all that wheezes is asthma!
}

\author{
Nem tudo que sibila é asma!
}

\author{
José Antônio Baddini Martinez
}

\section{To the Editor:}

Health professionals working in the field of respiratory diseases are used to finding, in the routine examination of patients, sounds to which we in Brazil give the standardized name of sibilos (wheezing). ${ }^{(1,2)}$ Wheezing is characterized by continuous, musical, adventitious breath sounds that last more than $250 \mathrm{~ms}$ and can appear during both inhalation and exhalation. In the English-language literature, the term wheeze is often employed to designate wheezing (higherpitched sounds) and another type of sound that, in Brazil, we prefer to call rhonchi (lower-pitched sounds). It is known that rhonchi and wheezing are produced by the appearance of oscillations in the airways and adjacent tissues because of the presence of severe airflow obstruction. The pitch differences between the two types of sound would depend on different frequencies of oscillation, which are higher in wheezing (approximately $400 \mathrm{~Hz}$ ) and lower in rhonchi (around $200 \mathrm{~Hz}$ ).

Wheezing is a common finding in patients with bronchospasm and airway obstruction. There is no doubt that one of the most common causes of wheezing complaints, or of auscultation of wheezing on physical examination, is bronchial asthma. Nevertheless, numerous other diseases can present with this sign. Examples of these conditions include tracheal stenosis, central airway tumors, pulmonary edema, and pulmonary aspiration. ${ }^{(2,3)}$

This is certainly the type of knowledge that is expected to be a required component of the basic education of all physicians, even of nonspecialists in respiratory medicine. However, to our surprise, in recent years, we have collected many clinical cases referred to our facility or private health care clinic for evaluation with a diagnosis of "severe asthma" or "difficult-to-control asthma" that are in fact cases involving completely different diseases. Many of these patients report for the appointment after long periods of investigation and unsuccessful treatments. Atopy testing and allergy desensitization therapy are common. Longterm use of high doses of systemic corticosteroids is the rule. The presence of severe side effects related to the last treatment is a constant, and these side effects contribute substantially to the deterioration of the patient's overall clinical status. In fact, in some cases, despite the diagnosis of "severe asthma", we never were able to detect a single episode of wheezing.

Asthma is a highly prevalent disease, and chronic recurrent episodes of dry cough, dyspnea, chest tightness, and wheezing are important for characterizing the disease. ${ }^{(4)}$ It should be borne in mind that not always all of these findings are present, which can make it difficult to diagnose asthma. On physical examination, wheezing is in fact the most common finding. Bronchial hyperresponsiveness is a characteristic of individuals with asthma, although it is not always present, depending on the treatment given or the type of definition employed. ${ }^{(4)}$ However, bronchial hyperresponsiveness can also be found in many other conditions, such as allergic rhinitis, COPD, right after respiratory infections, bronchiectasis, cystic fibrosis, heart failure, acute chest syndrome of sickle cell anemia, use of beta blockers, etc. ${ }^{(5-7)}$ All these conditions described can present with wheezing and certainly do not characterize asthma. In these situations, diagnoses of "COPD + asthma", "bronchiectasis + asthma", or "heart failure + asthma" are also unacceptable.

An early study used methacholine challenge testing in 34 patients complaining of wheezing, the etiology of which remained unclear. ${ }^{(8)}$ Wheezing complaints could only be attributed to asthma in 35\% of the cases. In that sample, the most common etiology of wheezing was the presence of secretions in the upper airways, usually after respiratory infection. It is known that the sounds heard by those patients originate from partial occlusion by secretions present at the level of the vocal cords. Similar results were obtained in another study, which included 441 patients with symptoms consistent with asthma, of whom $53.1 \%$ had a history of wheezing. ${ }^{(9)} \ln 48.3 \%$ of the 
Chart 1 - Causes of wheezing other than asthma.

\begin{tabular}{lll}
\hline $\begin{array}{l}\text { Extrathoracic upper airway } \\
\text { obstruction }\end{array}$ & $\begin{array}{l}\text { Intrathoracic upper airway } \\
\text { obstruction }\end{array}$ & Lower airway obstruction \\
\hline Postnasal drip & Tracheal stenosis & COPD \\
Vocal cord dysfunction & Airway tumors & Bronchiectasis \\
Hypertrophied tonsils & Foreign body aspiration & Pulmonary edema \\
Upper airway tumors & Intrathoracic goiter & Gastric aspiration \\
Retropharyngeal abscess & Tracheobronchomegaly & Pulmonary embolism \\
Laryngeal edema or stenosis & Tracheomalacia & Bronchiolitis \\
Laryngocele & Vascular compression & Cystic fibrosis \\
Vocal cord paralysis & & Carcinoid syndrome \\
Relapsing polychondritis & & Lymphangitic carcinomatosis \\
Cricoarytenoid arthritis & & Parasitic infections \\
Wegener's granulomatosis & & Bronchospasm of various causes \\
& & (anaphylaxis, toxic gas inhalation, \\
& & post-viral infection, drug-induced \\
& & cause, acute chest syndrome, etc.) \\
\hline
\end{tabular}

cases, no bronchial hyperresponsiveness was detected, and, in another $40.6 \%$, bronchial hyperresponsiveness was also associated with evidence of extrathoracic airway disorders, such as pharyngitis and sinusitis.

Asthma is an important disease because of its high prevalence and, if not diagnosed and treated properly, its high mortality. ${ }^{(4)}$ These facts fully justify the large number of educational campaigns, which have been carried out in recent decades, among the general population and health professionals. In Brazil, everything indicates that a significant portion of individuals with asthma remain misdiagnosed and mistreated. However, it has been reported that, in Canada, up to $41 \%$ of patients labeled as having asthma at the level of primary care do not fulfill diagnostic criteria for the disease. (10) In South Africa, much of what is labeled as asthma can be airflow obstruction secondary to tuberculosis, smoking, and occupational exposure. ${ }^{(11)}$ Therefore, clinicians working in various settings should always be careful not to diagnose patients with other diseases that often require very different approaches as having asthma.

The approach to patients complaining of wheezing, presenting with physical examination findings of wheezing, or both, requires careful clinical history taking, with an emphasis on triggers, improvement factors, duration of wheezing, and course of wheezing over time. It is essential that, in addition to upper airway symptoms and digestive and cardiac symptoms, all types of respiratory symptoms present be properly assessed. The personal histories should be carefully investigated, especially regarding history of diseases, smoking, and occurrence of environmental exposure. Physical examination must be complete and cannot be limited only to pulmonary auscultation. Routine chest $\mathrm{X}$-rays and spirometry, ideally with printing of the flow-volume curve and evaluation of bronchodilator response, are usually the most useful ancillary tests in this assessment.

Chart 1 lists the potential causes of wheezing, all of which should be considered in the differential diagnosis with asthma. ${ }^{(3,12)}$

In summary, wheezing is a complaint or physical examination finding that needs to be properly interpreted within a broad clinical context and within the individual clinical context of the patients who seek medical attention because of their disease. The phrase coined in the 1930s and attributed to the American otolaryngologist Chevalier Jackson will always remain current:

"Not all that wheezes is bronchial asthma."

José Antônio Baddini Martinez Associate Professor, Department of Clinical Medicine, Faculdade de Medicina de Ribeirão Preto da Universidade de São Paulo - FMRP-USP, University of São Paulo at Ribeirão Preto School of Medicine - Ribeirão Preto, Brazil 


\section{References}

1. Manço JC. Fundamentos da ausculta pulmonar. Medicina (Ribeiräo Preto). 1994;27(1/2):66-82.

2. Meslier N, Charbonneau G, Racineux JL. Wheezes. Eur Respir J. 1995;8(11):1942-8. http://dx.doi.org/10.118 3/09031936.95.08111942 PMid:8620967

3. Smyrnios NA, Irwin RS. Wheeze. In: Irwin RS, Curley FJ, Grossman RF, editors. Diagnosis and Treatment of Symptoms of the Respiratory Tract. Armonk: Futura Pub Co; 1997. p. 117-53.

4. Cruz AA, Fernandes AL, Pizzichini E, Fiterman J, Pereira LF, Pizzichini M, et al. Diretrizes da Sociedade Brasileira de Pneumologia e Tisiologia Para o Manejo da Asma - 2012. J Bras Pneumol. 2012;38(Suppl 1):S1-S46.

5. Sterk PJ, Fabbri LM, Quanjer PH, Cockcroft DW, O’Byrne PM, Anderson SD, et al. Airway responsiveness. Standardized challenge testing with pharmacological, physical and sensitizing stimuli in adults. Report Working Party Standardization of Lung Function Tests, European Community for Steel and Coal. Official Statement of the European Respiratory Society. Eur Respir J Suppl. 1993;16:53-83. PMid:8499055

6. Borges Mde C, Ferraz E, Vianna EO. Bronchial provocation tests in clinical practice. Sao Paulo Med J. 2011;129(4):243-9. http://dx.doi.org/10.1590/S151631802011000400008 PMid:21971900
7. Vendramini EC, Vianna EO, De Lucena Angulo 1, De Castro FB, Martinez JA, Terra-Filho J. Lung function and airway hyperresponsiveness in adult patients with sickle cell disease. Am J Med Sci. 2006;332(2):68-72. http://dx.doi.org/10.1097/00000441-200608000-00003 PMid:16909052

8. Pratter MR, Hingston DM, Irwin RS. Diagnosis of bronchial asthma by clinical evaluation. An unreliable method. Chest. 1983;84(1):42-7. http://dx.doi.org/10.1378/ chest.84.1.42 PMid:6861547

9. Bucca C, Rolla G, Brussino L, De Rose V, Bugiani M. Are asthma-like symptoms due to bronchial or extrathoracic airway dysfunction? Lancet. 1995;346(8978):791-5. http://dx.doi.org/10.1016/S0140-6736(95)91617-2

10. LindenSmith J, Morrison D, Deveau C, Hernandez P. Overdiagnosis of asthma in the community. Can Respir J. 2004;11(2):111-6. PMid:15045041

11. Ehrlich Rl, White N, Norman R, Laubscher R, Steyn K, Lombard $\mathrm{C}$, et al. Wheeze, asthma diagnosis and medication use: a national adult survey in a developing country. Thorax. 2005;60(11):895-901. http://dx.doi.org/10.1136/ thx.2004.030932 PMid:16263947 PMCid:1747242

12. Irwin RS. Evaluation of wheezing illnesses other than asthma in adults. In: UpToDate, Basow DS, editor. UpToDate. Waltham: UpToDate; 2013. 